\title{
3. Functional preoperative and intraoperative mapping and monitoring: increasing safety and efficacy in glioma surgery
}

\author{
*Malte Ottenhausen, MD, Sandro M. Krieg, MD, Bernhard Meyer, MD, and Florian Ringel, MD \\ Department of Neurosurgery, Klinikum rechts der Isar, Technische Universität München, Munich, Germany
}

Greater extent of resection (EOR) of low-grade gliomas is associated with improved survival. Proximity to eloquent cortical regions often limits resectability and elevates the risk of surgery-related deficits. Therefore, functional localization of eloquent cortex or subcortical fiber tracts can enhance the EOR and functional outcome. Imaging techniques such as functional MRI and diffusion tensor imaging fiber tracking, and neurophysiological methods like navigated transcranial magnetic stimulation and magnetoencephalography, make it possible to identify eloquent areas prior to resective surgery and to tailor indication and surgical approach but also to assess the surgical risk. Intraoperative monitoring with direct cortical stimulation and subcortical stimulation enables surgeons to preserve essential functional tissue during surgery. Through tailored pre- and intraoperative mapping and monitoring the EOR can be maximized, with reduced rates of surgery-related deficits.

http://thejns.org/doi/abs/10.3171/2014.10.FOCUS14611

KEY WORDS glioma; mapping; eloquent; cortical regions; monitoring; direct cortical stimulation

$\mathrm{D}$ ESPITE ongoing efforts to find effective treatments for infiltrative gliomas, progression of these tumors can only be slowed, and so far a curative treatment remains impossible. ${ }^{19,123}$ Although there haven been advancements in nonsurgical therapy and some pharmacological agents are being tested in clinical trials,$^{82}$ early surgery ${ }^{37}$ and gross-total resection (GTR) play an increasingly substantiated role in prolonging overall survival in highgrade and low-grade gliomas (LGGs) and in maintaining or improving patients' quality of life. . $10,37,38,40,95,103,107$

Surgical treatment of tumors in close proximity to important functional areas or so-called eloquent areas remains a challenge, and eloquent location is a risk factor for disease progression and poor overall survival. ${ }^{14,38}$ However, the knowledge of topographical anatomy is not sufficient to determine resectability of a tumor because it does not represent functional anatomy with its interindividual variations. Therefore, to identify the relation of a tumor to an eloquent area and to define resectability, several techniques (using true electrophysiological methods or surro- gate parameters of function) have evolved and have been increasingly used to guide glioma resections during recent years. Thereby, resection of tumors previously classified as unresectable became possible, with a tolerable morbidity. ${ }^{49}$

In the quest to maximize the extent of resection (EOR) and to minimize morbidity, the modern neurosurgical armamentarium includes techniques to locate and identify tumor tissue by image guidance, fluorescent dyes, and intraoperative MRI, ${ }^{1,16}$ and to map and monitor critical functional areas like motor and language function, which can be achieved prior to surgery by functional MRI (fMRI), diffusion tensor imaging fiber tracking (DTI-FT), magnetoencephalography (MEG), and navigated transcranial magnetic stimulation (nTMS) and intraoperatively by direct electrical stimulation of the cortex (direct cortical stimulation [DCS]) or subcortical white matter tracts (subcortical stimulation [SCS]).

Presently, mapping and monitoring of motor and language function pre- and intraoperatively are the most established techniques, and therefore this review focuses on

ABBREVIATIONS CST = corticospinal tract; DCS = direct cortical stimulation; DTI-FT = diffusion tensor imaging fiber tracking; EOR = extent of resection; fMRI = functional MRI; GTR = gross-total resection; LGG = low-grade glioma; MEG = magnetoencephalography; MEP = motor evoked potential; nTMS = navigated transcranial magnetic stimulation; SCS = subcortical stimulation.

SUBMITTED September 1, 2014. ACCEPTED October 31, 2014.

INCLUDE WHEN CITING DOI: 10.3171/2014.10.FOCUS14611.

DISCLOSURE Dr. Krieg is a consultant for BrainLAB.

* Drs. Ottenhausen and Krieg contributed equally to this work. 
these two functions. We present the currently available techniques in their order of perioperative use, which can primarily be divided into preoperative mapping, intraoperative mapping, and intraoperative monitoring (Table 1). Thereby, the different techniques of preoperative mapping serve as tools to determine resectability, to estimate surgical risk and the necessity for intraoperative monitoring, and to plan the resection, including the approach. Intraoperative mapping defines resection borders and controls for preservation of neurological functions.

\section{Preoperative Functional Mapping Functional MRI \\ Neurosurgical Use}

Although initially used primarily for scientific purposes, fMRI was quickly adopted for clinical purposes and has become a widely available clinical application for presurgical evaluation of functional areas prior to brain tumor surgery. ${ }^{61}$ In patients with tumors in eloquent brain regions, fMRI has been routinely used for many years as a noninvasive brain-mapping tool to guide neurosurgical treatment decisions (Fig. 1).

\section{Technical Details}

Technically, fMRI detects a surrogate parameter of neuronal activation, a blood oxygenation level-dependent effect from activation-induced perfusion-related changes in the blood oxygen level from neurovascular coupling. ${ }^{77}$ Thereby, fMRI depicts functional networks involved in an investigated function such as a motor or language task. These networks are not necessarily required or critical for the assessed function in its completeness, because neuronal activity measured indirectly by blood oxygen levels is globally assessed and a differentiation of essential versus nonessential areas for function is not possible.

\section{Current Evidence}

Several studies have investigated the accuracy of fMRI, presenting promising results concerning sensitivity and specificity to adequately predict motor function compared with DCS. ${ }^{36,56,94}$ In these studies, motor fMRI has been proven to be a reliable method to localize motor function, which facilitates surgical planning and reduces the time needed for intraoperative mapping. However, there are also contradictory studies showing a large deviation of fMRI-depicted areas compared with areas detected by electrophysiological methods such as DCS and nTMS, which should keep us thinking critically in terms of fMRI use for preoperative planning. ${ }^{27,50,51}$

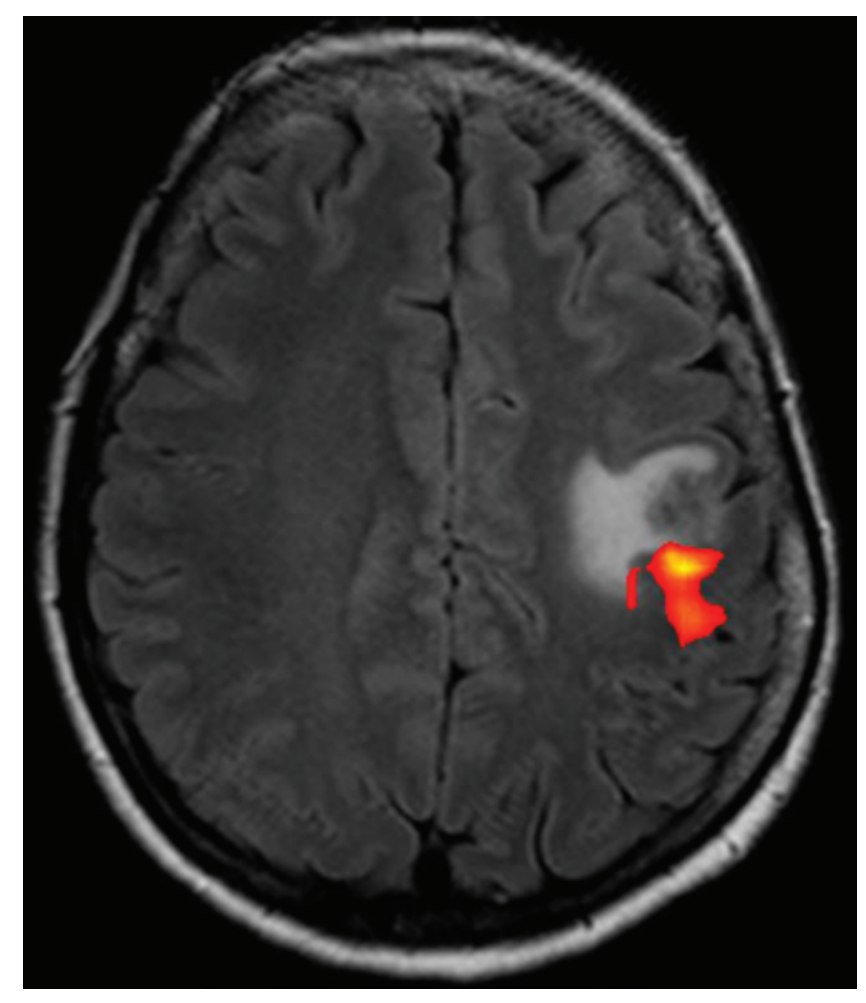

FIG. 1. Axial fMRI study showing a motor region dorsolateral to the LGG in the hand knob of the precentral gyrus.

\section{Limitations}

Especially in the vicinity of tumors, vascular changes can lead to a neurovascular uncoupling instead of the regular coupling and thereby produce false-negative fMRI results, making fMRI unreliable for resective planning. ${ }^{30,121}$ These false-negative results from neurovascular uncoupling could lead to the misinterpretation of eloquent tissue being noneloquent, and to subsequent resection with the associated neurological sequelae.

Concerning fMRI language localization, a review by Giussani et al. summarized the available data and evaluated the reliability of presurgical fMRI language mapping compared with DCS from 9 different studies. ${ }^{32}$ Several of the studies that these authors summarized investigated the sensitivity and specificity of fMRI in mapping language function.9,62,93,120,126 Because different language tasks and different MRI machines, software, analysis paradigms, and algorithms were used, the specificity and sensitivity for presurgical language localization by fMRI was highly variable. Five studies provided sufficient statistical data showing that sensitivity ranged from $59 \%$ to $100 \%$ and that specificity ranged from $0 \%$ to $97 \%$ compared with intra-

TABLE 1. Overview of the most frequently used pre- and intraoperative techniques for cortical and subcortical mapping and monitoring of motor and language function

\begin{tabular}{clccccc}
\hline & \multicolumn{2}{c}{ Motor Function } & & \multicolumn{2}{c}{ Language Function } \\
\cline { 2 - 3 } Technique & \multicolumn{2}{c}{ Cortical } & Subcortical & & Cortical & Subcortical \\
\hline Preop mapping & fMRI, MEG, nTMS & DTI-FT & & fMRI, MEG, nTMS & DTI-FT \\
\hline Intraop mapping & DCS & \multicolumn{2}{c}{ SCS } & & DCS & SCS \\
\hline Intraop monitoring & & Continuous DCS & & Awake language monitoring \\
\hline
\end{tabular}


operative DCS mapping during awake surgery. These data show that fMRI in its present form cannot be used reliably to guide resections of tumors close to eloquent areas. It can certainly give a presurgical impression of functional organization; however, neurovascular uncoupling and potential false-negative results always have to be kept in mind.

At present, fMRI motor and language mapping is not able to detect critical functional areas reliably prior to surgery and cannot be recommended for planning of resective surgery of tumors in a potentially eloquent location. It can only serve as an adjunct to other methods, especially intraoperative electrical stimulation mapping.

\section{Magnetoencephalography \\ Neurosurgical Use}

So far, MEG has been applied for central sulcus localization, primary auditory and visual cortex delineation, language lateralization, and localization of the motor cortex. Several studies have assessed the feasibility of MEG motor or language mapping prior to surgery.

\section{Technical Details}

Magnetoencephalography is the detection of magnetic fields produced by bioelectric currents from neuronal activation, which means it is a direct measurement of cortical activity ${ }^{63}$ To detect magnetic fields produced by cerebral electric activity at pico- or femtotesla levels, supraconductive sensors and magnetically shielded environments are necessary. Use of MEG allows the detection of spontaneous activity or evoked activity time-locked to certain stimuli. The coregistration of MEG source localization with anatomical MRI allows the use of this technique in presurgical localization of activity and surgical planning. The MEG data obtained during motor tasks can be used to reconstruct spatiotemporal dynamics of brain sources.

\section{Current Evidence}

To assess MEG accuracy, some studies compared preoperative MEG motor mapping with intraoperative DCS in patients with brain tumors and found a reliable delineation of MEG motor areas in comparison with intraoperative DCS. ${ }^{42,45,65,99,117}$ Tarapore et al. compared nTMS and MEG motor mapping with intraoperative DCS in patients with brain tumor and found a deviation of nTMS, MEG, and DCS motor sites of 4.7-2.1 mm. ${ }^{117}$ The use of MEG for motor mapping confirmed functional activity within LGGs, ${ }^{100}$ and all patients who had functional tissue located within the tumor and who underwent GTR despite this finding suffered from new neurological deficits after surgery, showing the predictive accuracy of MEG..$^{100}$

The experience with MEG for presurgical language mapping is limited. Only a few studies have assessed language prior to surgery and revealed a good agreement with intraoperative electrophysiological language mapping. ${ }^{84,102}$ Tarapore et al. recently published a study reporting their results for mapping language function via DCS, nTMS, and MEG. ${ }^{117}$ In 12 patients in whom language sites were outlined by MEG for verb generation and object naming, the sites correlated with nTMS sites in 5 of these patients and with DCS sites in 2.
Earlier MEG studies of language lateralization have demonstrated promising results. As discussed by Tarapore et al., ${ }^{116}$ although MEG lacks the accuracy of TMS, Findlay et al. have highlighted the use of MEG for a more global analysis of language lateralization that even predicted surgical outcome for patients with eloquent gliomas. ${ }^{27,116}$

Concerning presurgical risk assessment based on MEG data for a neurological complication from lesion resection, a series of 119 patients was published. In this patient series $46 \%$ were not treated surgically because of tumor invasion of eloquent cortex as assessed by MEG, whereas 54\% underwent resection on MEG mapping, with an associated neurological deterioration of $6 \% .^{31}$

\section{Limitations}

Although MEG is efficient in terms of temporal and spatial resolution, the distribution of MEG mapping is still limited due to the high costs of the modality and as a consequence its limited availability. Therefore, the amount of data presently available for tumor resection is still quite scarce.

\section{Navigated TMS \\ Neurosurgical Use}

Transcranial magnetic stimulation is an older technique, which uses a transcranial magnetic field to elicit a cortical electrical field and thus neuronal activation or inhibition. The integration of TMS in an adjusted navigation system made it available for presurgical functional mapping, because this allows for an exact cortical representation of stimulation or inhibition by TMS and the induced or inhibited functional response. Single-pulse TMS is readily used for motor response stimulation, whereas repetitive TMS inhibits functional activation, leading to a so-called virtual lesion, which has been recently used for language mapping.

\section{Technical Details}

Navigated TMS is a unique method for mapping essential brain function due to a fundamental difference between TMS and other functional brain imaging tools such as fMRI and MEG. When stimulated or inhibited cortical areas evoke a measurable physiological response, these areas are mandatory; i.e., essential to the observed reaction. Other imaging methods such as fMRI and MEG detect and map all brain areas that participate in a given task or reaction; i.e., the entire network that is responsible for the reaction, without differentiating essential from nonessential areas.

\section{Current Evidence}

Navigated TMS has recently proven to be suitable for clinical mapping of the cortical motor areas and for the simultaneous assessment of the functional status of the motor tracts. ${ }^{27,28,39,47,50,104,117}$ For a detailed evaluation of their mapping accuracy, the noninvasive nTMS method and the DCS cortical map of motor function were compared by calculating the distances between the respective hot spots or centers of gravity of target muscles. Although there are various methodological flaws inherent to this approach- 
from the navigational error to the misconception of one hot spot or stable center of gravity for each muscle-all studies on nTMS mapping accuracy reported distances between both methods of 1.1 and $14.8 \mathrm{~mm}$ for the hot spot comparison of the adductor pollicis brevis muscle. ${ }^{27,51,86,117}$

Due to the low expense of nTMS and the ease of use associated with the sufficient accuracy of this true electrophysiological method, an increasing number of centers use presurgical nTMS mapping when gliomas are located in or near eloquent areas.

Concerning presurgical planning, one study showed that brain mapping by nTMS influenced the surgical approach and the planned EOR, and even changed the indication in a small group of patients. ${ }^{86}$ Furthermore, it has been demonstrated that tumor-infiltrated eloquent tissue that prevented total tumor resection can become resectable due to functional reorganization over time as assessed by nTMS. ${ }^{86,112}$

Recently, the first study addressing the impact of nTMS on the oncological and functional outcome of brain tumor surgery was published. ${ }^{47}$ The study compared the outcomes of 100 patients treated with preoperative nTMS examination to those of patients in a matched in-house historical pre-nTMS group and revealed better neurological outcomes combined with increased EOR in the nTMSmapped patient cohort. A similar second study revealed that these beneficial effects of preoperative nTMS also occurred in a subgroup of patients with LGGs. ${ }^{28}$ The authors provided data that nTMS caused a conversion of the treatment approach from biopsy or no surgery to surgery in 37 of 54 patients $(68.5 \%)$.

Additionally, cortical nTMS mapping results can serve as a measure to standardize the visualization of subcortical motor fiber tracts. The cortical outline of essential motor areas by nTMS can be used as a seed region for initiation of a fiber tracking algorithm, leading to a more accurate and reproducible delineation of subcortical fibers than can be obtained with the standard tracking approach. ${ }^{29,46}$ This method has recently been shown to contribute to preoperative risk stratification by measuring the distance between subcortical tumors and the corticospinal tract (CST) as outlined by nTMS-based DTI-FT. The authors demonstrated that none of the 205 patients showed surgery-related paresis when the minimal distance between tumor and CST was larger than $10 \mathrm{~mm} .{ }^{28}$

Whereas the protocol for nTMS motor cortical mapping is well established and reliable, nTMS language mapping for neurosurgical patients performed using repetitive TMS stimulation is still evolving. Even so, the first published series including the first tested protocol has already reported a good overall correlation between repetitive nTMS and DCS, which was especially true for negatively mapped brain regions, resulting in a high negative predictive value..$^{85}$ Nonetheless, the insufficient specificity in posterior perisylvian language areas demands further refinements of the mapping protocol, a difficulty that already has been partially overcome by modifications. ${ }^{55}$

Navigated TMS language mapping has already been used as a tool for follow-up examinations prior to repeated awake surgery and to detect a shift of language function to the contralateral perisylvian region, and this method is therefore able to visualize language plasticity in patients with brain tumor. ${ }^{53,54,91}$

\section{Limitations}

nTMS motor mapping has proven to be beneficial in treatment planning for the resection of tumors close to eloquent regions, but this technique has limitations. Although mapping results obtained prior to surgery are useful, choosing an approach using presurgical mapping does not allow the surgeon to waive intraoperative electrical stimulation mapping and monitoring. Moreover, although nTMS serves to estimate resectability, EOR, and surgical approaches, and to define starting points for intraoperative electrical stimulation, nTMS language mapping will not allow the general abandonment of awake language mapping. However, this method could reduce awake mapping time, and for only a small subgroup of patients unable to undergo mapping while awake or electrical stimulation while asleep, presurgical nTMS mapping can reduce the surgical risk.

\section{Diffusion Tensor Imaging Fiber Tracking \\ Neurosurgical Use}

Although fMRI, MEG, and TMS allow for cortical localization of neurological function, none of these techniques is able to delineate subcortical white matter tracts arising from or connecting relevant cortical areas. Again, the aim of presurgical functional localization is to assess lesion resectability and surgical risk prior to taking the patient to the operating room and to provide intraoperative orientation regarding when to expect relevant subcortical fibers and when to initiate subcortical electrical stimulation mapping during surgery. ${ }^{5,11}$

\section{Technical Details}

Only a single technique-DTI-FT_-is available to noninvasively depict subcortical white matter tracts, the preservation of which is also important to maintain neurological functions. ${ }^{15,73-75,105,106}$ However, the reconstruction of subcortical fiber tracts from diffusion tensor vectors is a purely anatomical imaging analysis that does not include true electrophysiological functional data.

\section{Current Evidence}

Particularly for preoperative mapping of the CST in relation to a tumor, DTI-FT is a commonly used technique. $2,5,8,73,78,106$ Various studies have investigated the accuracy of pre- and intraoperative DTI-FT compared with intraoperative SCS mapping of the motor pathways, which revealed mostly good intraoperative correlations of DTI-FT and SCS, depending on intraoperative brain shift. ${ }^{78,81,127,128}$ The sensitivity of CST detection was $95 \%$ in a series by Bello et al., ${ }^{6}$ and the sensitivity was $93 \%$ at a specificity of $93 \%$ in a series by Zhu et al. Several reports have shown that especially in LGGs, fibers were frequently located inside the tumor, and DTI-FT was able to visualize these fibers. ${ }^{5,6,78}$ This aspect contributes to the estimation of resectability. In a series of 73 gliomas, Castellano et al. revealed that an infiltration or displacement of the DTI-FT CST was associated with a lower probabil- 
ity of total tumor resection. ${ }^{12}$ In a prospective randomized trial including 238 patients, the presurgical DTI-FT of the CST and inclusion in the neuronavigation system did lead to a larger EOR, an improved clinical outcome with regard to new deficits, and improved overall functional status in comparison with the control group without FT. ${ }^{125}$

However, in addition to the limitation of solely anatomical fiber delineation, a major limitation of the intraoperative use of DTI-FT when integrated into neuronavigation is the brain shift, which has already happened when subcortical fibers are reached during a tumor resection. A study by Nimsky et al. revealed CST shifts at a range from -8 to $15 \mathrm{~mm}$, where direction of shift was not predictable. ${ }^{74}$ Thus, DTI-FT is a valuable additional tool for preoperative planning, but it requires a strict control modality when used intraoperatively within the navigation systems during resection of tumors close to the CST; that control is intraoperative electrical stimulation mapping. ${ }^{74,83,127}$

The introduction of nTMS in neurosurgical planning led to the fusion of the neurophysiologically based nTMS motor mapping and DTI-FT as a pure imaging technique by using the motor cortex as outlined by nTMS as a seed region for DTI-FT. Two recently reported studies have investigated this approach and both found a higher grade of standardization of DTI-FT when combined with nTMS..$^{29,46}$ Moreover, this technique can be used to clarify highly impaired and unclear functional anatomy prior to surgery and enable the surgeon to get a better understanding of the essential structures, which have to be preserved (Fig. 2).
Apart from motor system tracking, DTI-FT can also be used to noninvasively visualize language tracts such as the arcuate fasciculus and the inferior frontooccipital fasciculus, and comparisons of this method to intraoperative electrical stimulation have been published. ${ }^{5,34,57,58,74}$ Similar to mapping of the CST, SCS for language tracts also correlated well with preoperative DTI-FT, with a sensitivity of $97 \% .{ }^{5}$ As for motor tracts, a displacement or infiltration of subcortical language fiber tracts is predictive for a lower probability of a complete resection. ${ }^{12}$

\section{Limitations}

It remains unclear whether DTI-FT of language tracts based on cortical nTMS language representation would also be beneficial. This approach is currently being evaluated in our department, but studies on the value of such an approach are still lacking. Figure 3 gives an impression of combined cortical and subcortical nTMS-based planning to determine areas of language and motor function prior to surgery.

\section{Intraoperative Electrical Stimulation Mapping and Monitoring}

\section{Neurosurgical Use}

Whereas presurgical functional mapping serves as a tool to plan surgical treatments of tumors close to eloquent areas, intraoperative electrical stimulation techniques aim to guide resection in an attempt to achieve maximum re-

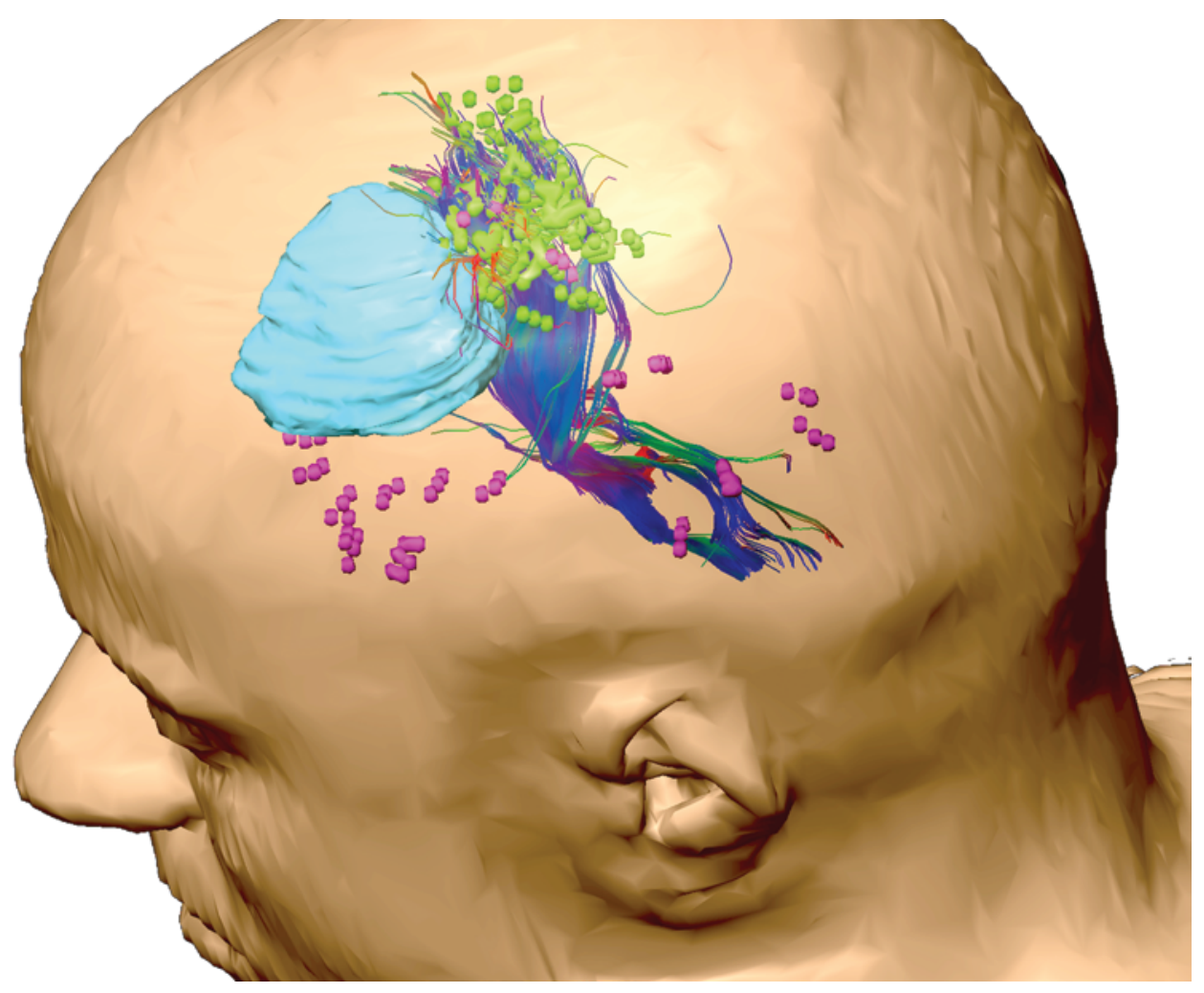

FIG. 2. Navigated TMS is able to clarify highly impaired and unclear functional anatomy prior to surgery and enables the surgeon to get a better understanding of the essential structures, which have to be preserved. Green = motor cortex; light blue = LGG; dark blue $=$ nTMS-based DTI-FT of the CST; dark pink = language-involved cortex . 


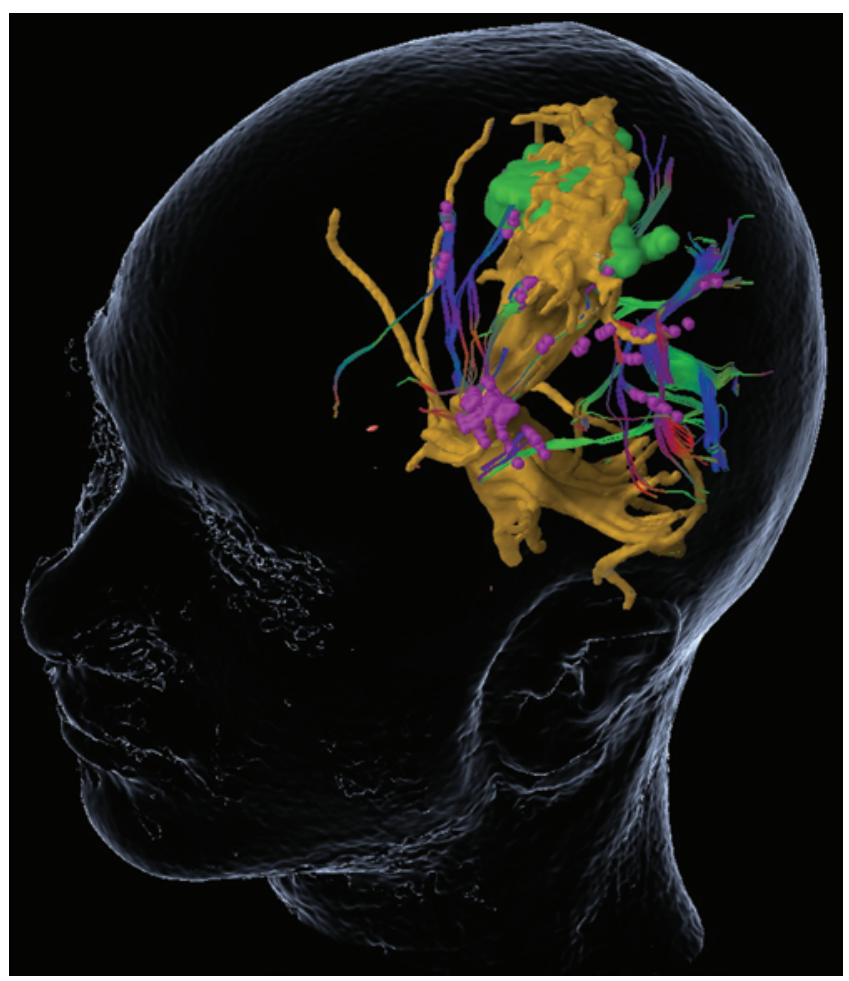

FIG. 3. This neuronavigational 3D screenshot gives an impression of a combined cortical and subcortical nTMS-based planning image obtained prior to surgery for language (dark pink) and motor function (green) including nTMS-based DTI-FT of the CST (yellow) and language tracts such as the arcuate fascicle (blue).

section with minimal risk for neurological deficits, and these techniques serve as the gold standard for functional mapping and monitoring.

\section{Technical Details}

At present, different techniques for intraoperative stimulation are available: for intraoperative localization of functional areas, so-called mapping, a low-frequency $50-$ or $60-\mathrm{Hz}$ stimulation technique or a high-frequency train-of-five stimulation using either monopolar or bipolar stimulation, is used for cortical or subcortical functional localization. Furthermore, a sequential repetitive cortical stimulation performed using the train-of-five technique can be used for motor evoked potential (MEP) monitoring to continuously assess the integrity of the CST. Whereas motor mapping can be performed in an asleep or awake setting, for language mapping awake surgery is required.

\section{Current Evidence}

The intraoperative mapping and monitoring techniques that are available have been increasingly used in the last decade, and various studies have reported beneficial effects. ${ }^{14,18,25}$ Although its use was doubted by many surgeons years ago, there is increasing evidence for the high value of intraoperative DCS mapping. ${ }^{18,25}$

Already in 2005 an analysis by Duffau et al. compared a series of patients with LGG that was resected with intraoperative electrical stimulation with patients in a historic control group in which operations were not performed with the aid of stimulation mapping. The mapping group consisted of more patients with eloquently located LGG, and the rate of severe permanent deficits decreased from $17 \%$ to $6.5 \%$ in the mapping group while the rate of GTR increased ${ }^{26}$ Furthermore, a recent meta-analysis on 8091 patients strengthened the evidence for stimulation mapping even more. In this analysis, late severe neurological deficits were observed in $3.4 \%$ of patients with intraoperative DCS mapping and in $8.2 \%$ of patients after resections performed without DCS mapping. Moreover, GTR was $75 \%$ with and $58 \%$ without stimulation mapping. ${ }^{18}$ The use of electrical stimulation mapping has an oncological (by increasing the EOR) and neurological (by reducing the incidence of new neurological deficits inflicted by surgery) benefit for patients with eloquently located tumors. ${ }^{18}$

\section{Motor Mapping and Monitoring \\ Cortical Monitoring and Mapping}

For intraoperative mapping and monitoring of motor function, different methods are available at a cortical or subcortical level to identify and monitor cortical motor areas or the subcortical tracts.

Continuous transcranial or cortical MEP monitoring is performed by stimulation of the motor cortex by using a train-of-five stimulation technique. ${ }^{13,115}$ Resulting MEPs are recorded by extremity electromyography, and the latency and amplitude are evaluated online for any changes during surgery. Certain criteria for a significant MEP change with predictive value concerning motor outcome have been described, as follows: 1) an amplitude reduction of $50 \%$ or more, $43,44,66,67,69,71,72,108$ or 2 ) a necessary $\geq$ 4-mA increase in stimulation energy to maintain amplitude height. ${ }^{101}$ However, the majority uses a $50 \%$ or more amplitude decline as a significant warning criterion..$^{52,69,96}$

Reversible MEP amplitude declines of $50 \%$ or more are generally associated with temporary motor deficits, whereas irreversible MEP declines or an MEP loss predicts a permanent new motor deficit. ${ }^{48,66,68-70,109,110}$ Recently the reliability of this modality in terms of potentially false-negative events was investigated, proving that these events are mainly due to secondary injury to the motor system (hemorrhages, secondary ischemia) or resections in supplementary motor areas resulting in temporary motor deficits. ${ }^{52}$ This study clarified that postoperative events such as hematoma causing deterioration of motor function do not represent false-negative results when MEPs have remained stable during surgery. ${ }^{52}$

The question arises whether MEP monitoring provides warning information resulting in a change of surgical strategy and potential return to baseline MEP signals or whether this monitoring provides predictive information for motor outcome only. In a series reported by Seidel et al., most MEP declines occurred abruptly and were reversible in only $60 \%$ of cases..$^{101}$ Thus, the warning function of MEP monitoring is limited and the predictive value for motor outcome predominates.

\section{Subcortical Mapping}

To guide resections close to the motor pathways, cortical and subcortical mapping of the motor system are frequent- 
ly used. For subcortical and cortical mapping stimulation, two different techniques are available: $50-$ or $60-\mathrm{Hz}$ lowfrequency stimulation or a high-frequency train-of-five stimulation as used for motor monitoring. This monitoring can be used as bipolar or monopolar stimulation (anodal cortical stimulation and cathodal subcortical stimulation). Whereas Berman et al. ${ }^{8}$ used $60-\mathrm{Hz}$ bipolar stimulation with stimulation intensity ranging from 8 to $12 \mathrm{~mA}$, Ohue et al. ${ }^{78}$ used a train-of-five monopolar cathodal stimulation from 5 to $20 \mathrm{~mA}$ and Mikuni et al. ${ }^{64}$ used $50-\mathrm{Hz}$ bipolar stimulation without reporting any stimulation intensity.

There are a vast number of other studies reporting on bipolar, monopolar anodal, and monopolar cathodal stimulation applied as a train, which mostly concluded in a linear correlation of current and distance to the CST. ${ }^{76,83,88}$ Concerning this stimulation setup, Szelényi et al. performed a highly cited and crucial study comparing train application with the single-pulse technique as well as bipolar and monopolar stimulation. ${ }^{111}$ It was found that the CST is most efficiently identified using a multipulse train technique with a monopolar probe. Additionally, results of a large series of patients who underwent subcortical motor mapping were recently published, comparing the $60-\mathrm{Hz}$ low-frequency technique to the train-of-five stimulation technique for subcortical motor mapping in patients with tumors involving the CST. This study revealed that in most situations highfrequency stimulation is superior to the older $50-$ or $60-\mathrm{Hz}$ technique in its efficacy in identifying subcortical motor fibers., ${ }^{4,6}$ Train-of-five high-frequency stimulation seems to be the superior technique to stimulate MEPs from subcortical CST. Thereby, the MEP threshold (i.e., the energy necessary to elicit a peripheral MEP response) reflects the distance between the stimulation point and the CST. There have been attempts to provide a direct transfer between stimulation intensity and distance to the CST. These studies reported a linear correlation between the SCS intensity at which an MEP could be elicited and the distance to the CST. Although this correlation is still under discussion, the majority of neurosurgeons presume a linear correlation of 1 $\mathrm{mA}$ of stimulation equals approximately $1 \mathrm{~mm}$ of distance of the stimulation point to the CST. ${ }^{64,76,78,88}$

Recently we published our own evaluation of the relation of stimulation distance and stimulation energy. These data revealed that the distance-to-energy relationship is not linear and that stimulation points are closer than assumed from the " $1 \mathrm{~mA}$ resembles $1 \mathrm{~mm}$ " rule. In this study we were able to safely resect toward the CST until a threshold of $3 \mathrm{~mA}$, which is approximately a distance of $2 \mathrm{~mm}$. Some other studies also defined electrical safety margins (i.e., at which stimulation intensity at the white matter of the resection cavity the resection should be stopped to avoid injury to the CST) ${ }^{41,64,89,96}$ with consecutive surgery-related paresis. Although this safety margin was reported to be $6 \mathrm{~mA}$ for some time, a new study on continuous SCS as permanent monitoring of the CST used 1-3 mA in 24 of 67 cases without any new surgery-related permanent paresis. ${ }^{89}$

For many experienced neurosurgeons, SCS is the most reliable method for estimating the proximity to the CST during resection within the white matter. ${ }^{5,8,40,41,89}$ Thus, neurosurgeons are able to perform safer and even more radical tumor resections close to the $\mathrm{CST}{ }^{23,41}$

\section{Cortical and Subcortical Language Mapping \\ Cortical Monitoring and Mapping}

The meta-analysis by De Witt Hamer et al. included not only motor but also language eloquent tumors and therefore the corresponding DCS mapping. ${ }^{18}$ Thus, there are sufficient data at hand to demonstrate that it is difficult to operate on patients with left-sided perisylvian LGG without performing any intraoperative awake DCS mapping.

One large series on awake surgery for patients with glioma showed that only 4 of 243 patients (1.6\%) suffered from any surgery-related permanent language deficit 6 months after surgery, and reported a GTR rate of $51.6 \%$ in patients with LGG. .3, $^{39,80,97}$

Moreover, as also shown in recent studies, DCS mapping during awake surgery can provide cortical maps of language function, which showed a high variability within the dominant hemisphere among the patients investigated. . $^{32,80,97}$

However, language mapping requires awake mapping, which has become a common tool in contemporary neurosurgery. ${ }^{97}$ Awake craniotomy is well accepted and failure rates are low. ${ }^{3,76}$ For mapping of language function during awake surgery, various protocols have been published. The most commonly used is presented in this review. Craniotomy should at least expose the tumor and up to $3 \mathrm{~cm}$ of surrounding brain surface. One-millimeter bipolar electrodes positioned $5 \mathrm{~mm}$ apart are used, starting with a low stimulus of a constant current with 1.5-mA square-wave pulses and increased to a maximum of $6 \mathrm{~mA}$. A generator delivers biphasic trains of 50 or $60 \mathrm{~Hz}$ (depending on the electrical currents used in a particular country). The cortex is mapped every $5-10 \mathrm{~mm}$, and positive stimulation sites at which language impairment was caused are marked with sterile numbered tickets (Figs. 4 and 5). Language tasks usually include systematic counting, naming, and reading; repetition and semantic tasks can be used as well, depending on the primary tumor location..$^{25,97,113}$

Most importantly, continuous electrocorticography can be used to monitor afterdischarge potentials, and therefore eliminate the chance that language is impaired by focal seizures.

\section{Subcortical Mapping}

Awake surgery not only allows mapping of cortical language sites by DCS, but also enables mapping and monitoring of subcortical language tracts.96,97

Duffau et al. recently described the hodotopical model of language function. ${ }^{26}$ This model (hodotopical means a delocalized and dynamic model of language function) argues that the language network is organized in widespread, corresponding, separated cortico-subcortical subnetworks for syntactic, semantic, and phonological function. ${ }^{26,122}$ This parallel organization makes it possible for language function to recover after impairment of subnetworks due to resection or surgery-related ischemia. Yet this model, which also highly corresponds with clinical experience, makes it even more important not only to map cortical language sites during awake surgery but also to map and monitor subcortical fiber tracts during LGG resection. ${ }^{17,24,96}$

Concerning the technical aspect of subcortical map- 


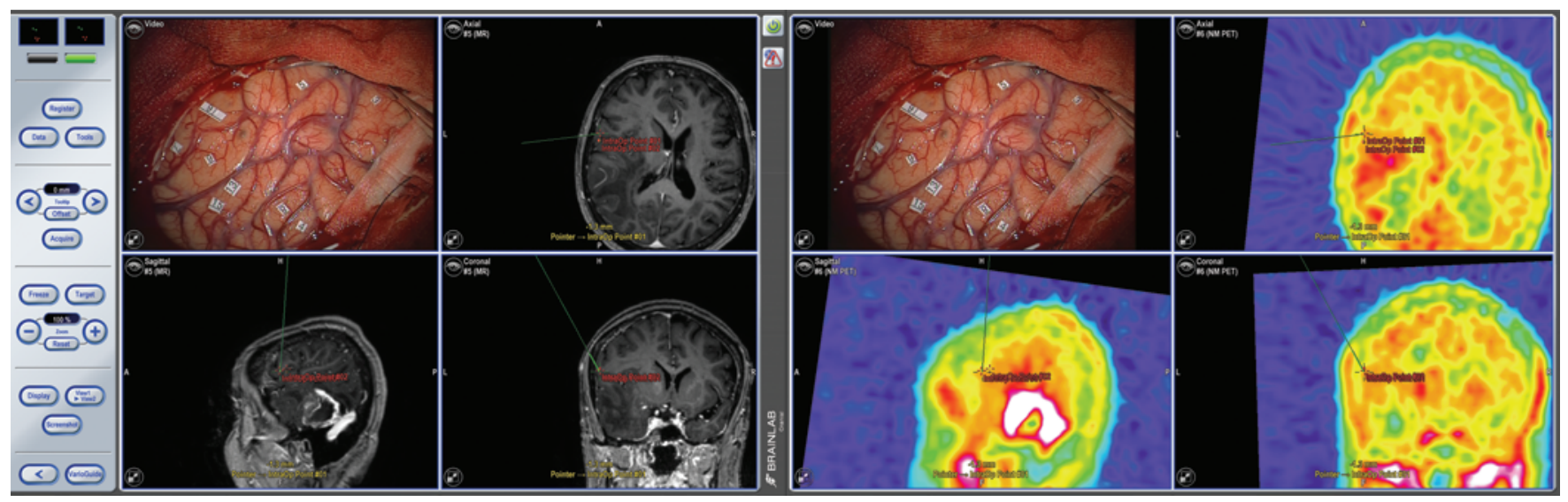

FIG. 4. This neuronavigational screenshot shows language mapping via DCS during awake surgery by a navigated pointer (green). The cortex is mapped every 5-10 mm (microscope view), and positive stimulation sites at which language impairment was caused are marked with sterile numbered white tickets.

ping of language function, the same 5-mm spaced bipolar electrodes with a biphasic current (pulse frequency 50 or $60 \mathrm{~Hz}$ ) are used, with a stimulation intensity of 2-6 mA and the same language tasks as for cortical mapping, depending on the targeted subcortical tract. ${ }^{25}$

Parallel to the mapping of cortical language areas and subcortical language tracts, awake surgery also enables continuous monitoring of language function by use of language tasks given by a trained neuropsychologist even during tumor resection. ${ }^{55,85,113}$

\section{Future Directions}

The techniques presented in this review have evolved significantly within recent years. Through functional mapping, treatment of gliomas within eloquent brain regions has been changed: indications have increased and overall survival and surgery-related deficits have been optimized. Although the possibilities of the techniques presented are immense, so are, for now, their limitations. The most important task in the near future is to improve their accuracy

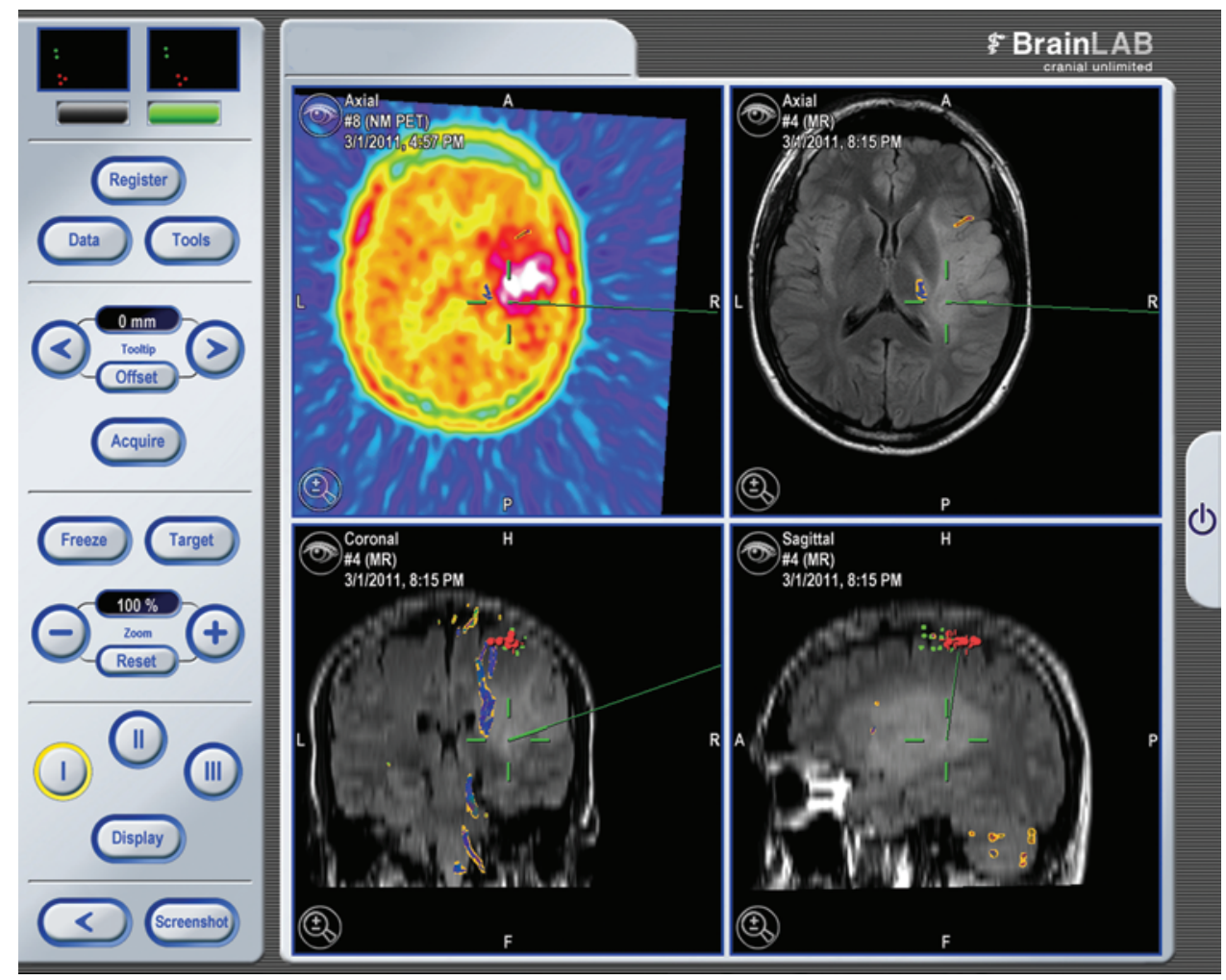

FIG. 5. This neuronavigational screenshot shows a large insular LGG. During surgery SCS is performed, with a navigated probe (green) used to map the subcortical fibers (yellow and blue). The red dots show cortical motor cortex as identified by DCS. Subcortical stimulation is performed by measuring the amount of electric current necessary to elicit an MEP, and transfers this current into an actual distance to the fiber tract such as the CST (yellow and blue). 

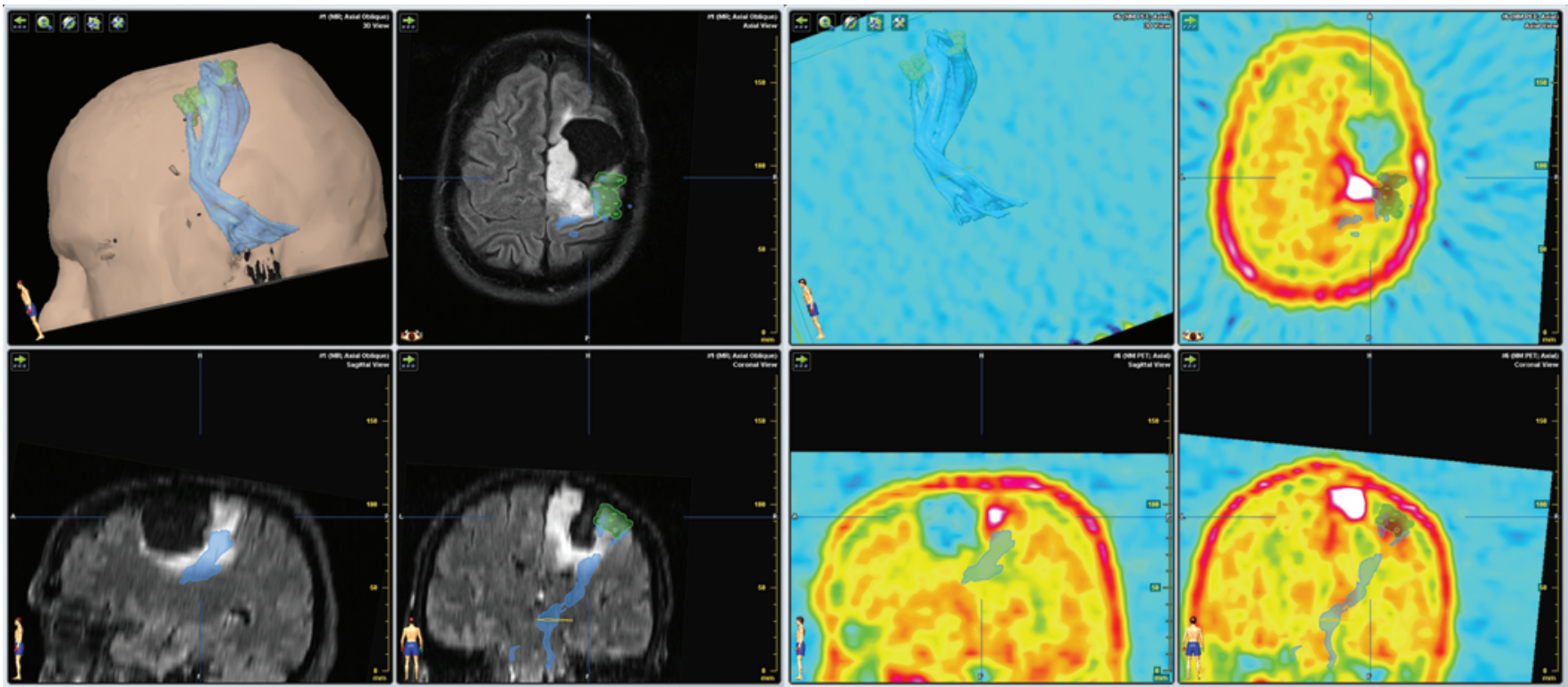

FIG. 6. Navigated TMS is able to reveal tumor-induced plasticity for motor function (green), as in this case in which nTMS shows a shift of motor function to the lateral precentral gyrus (green) away from the PET-positive (4 panels on the right) region of an LGG in the medial precentral gyrus. Navigated TMS-based DTI-FT was also used (blue).

and conduct prospective studies to reach higher levels of evidence.

Whereas pre- and intraoperative mapping and monitoring of motor and language function has already been established, the possibilities of neuropsychological or cognitive mapping and monitoring should be investigated more intensively. Several authors have already highlighted the importance of neuropsychological testing before, during, and after glioma surgery. ${ }^{22,98,114,124}$ The clinical relevance of monitoring other cognitive functions like calculation ${ }^{20}$ has been shown.

Navigated TMS is not only able to map function but also to modulate it. ${ }^{21}$ Recent studies have shown its impact on connectivity within functional networks and therapeutic applications in a wide range of diseases-depression, ${ }^{87}$ acute $^{119}$ and chronic ${ }^{59,60}$ pain, and epilepsy $y^{18,119}$ are under investigation. Moreover, TMS has been considered useful in neurocognitive rehabilitation. ${ }^{92}$

Moreover, it was repeatedly shown that nTMS can reveal tumor-induced plasticity for motor as well as for language function (Fig. 6). ${ }^{35,39,53,90,91}$ Whether and with what incidence this possibility is able to change surgical indications or the clinical course will be shown soon.

From our perspective, more surgeons need to acquire expertise in the already well-established techniques such as MEP mapping and monitoring, and some centers should also concentrate on increasing the knowledge of new techniques and their actual value in patient care.

\section{Conclusions}

Through thoughtful pre- and intraoperative mapping and monitoring the EOR can be maximized, with low rates of surgery-related deficits. The available techniques are feasible and should be used in all glioma resected with functional location surgery. Motor and language functions are already monitored successfully, and neuropsychologi- cal functions will also be more commonly monitored in the near future. As image-guided surgery is evolving to increase EOR, the indications for and possibilities of brain mapping are extended-these techniques should be used together to optimize surgical results. While improving surgical results, these techniques also help us to understand the complex neuronal architecture of the brain.

\section{References}

1. Barone DG, Lawrie TA, Hart MG: Image guided surgery for the resection of brain tumours. Cochrane Database Syst Rev 1:CD009685, 2014

2. Bauer MH, Barbieri S, Klein J, Egger J, Kuhnt D, Freisleben $\mathrm{B}$, et al: Boundary estimation of fiber bundles derived from diffusion tensor images. Int J CARS 6:1-11, 2011

3. Beez T, Boge K, Wager M, Whittle I, Fontaine D, Spena G, et al: Tolerance of awake surgery for glioma: a prospective European Low Grade Glioma Network multicenter study. Acta Neurochir (Wien) 155:1301-1308, 2013

4. Bello L, Comi A, Riva M, Pessina F, Alfiero T, Raneri F, et al: Glioma surgery: tailoring intraoperative neurophysiological strategies to clinical conditions enhances resection, extends indications, and keeps patient functional integrity. Neuro Oncol 16 (Suppl 3):iii47, 2014 (Abstract)

5. Bello L, Gambini A, Castellano A, Carrabba G, Acerbi F, Fava E, et al: Motor and language DTI fiber tracking combined with intraoperative subcortical mapping for surgical removal of gliomas. Neuroimage 39:369-382, 2008

6. Bello L, Riva M, Fava E, Ferpozzi V, Castellano A, Raneri F, et al: Tailoring neurophysiological strategies with clinical context enhances resection and safety and expands indications in gliomas involving motor pathways. Neuro Oncol 16:1110-1128, 2014

7. Berger MS, Deliganis AV, Dobbins J, Keles GE: The effect of extent of resection on recurrence in patients with low grade cerebral hemisphere gliomas. Cancer 74:1784-1791, 1994

8. Berman JI, Berger MS, Chung SW, Nagarajan SS, Henry RG: Accuracy of diffusion tensor magnetic resonance imaging tractography assessed using intraoperative subcortical stimu- 
lation mapping and magnetic source imaging. J Neurosurg 107:488-494, 2007

9. Bizzi A, Blasi V, Falini A, Ferroli P, Cadioli M, Danesi U, et al: Presurgical functional MR imaging of language and motor functions: validation with intraoperative electrocortical mapping. Radiology 248:579-589, 2008

10. Capelle L, Fontaine D, Mandonnet E, Taillandier L, Golmard JL, Bauchet L, et al: Spontaneous and therapeutic prognostic factors in adult hemispheric World Health Organization Grade II gliomas: a series of 1097 cases. Clinical article. J Neurosurg 118:1157-1168, 2013

11. Carrabba G, Fava E, Giussani C, Acerbi F, Portaluri F, Songa $\mathrm{V}$, et al: Cortical and subcortical motor mapping in rolandic and perirolandic glioma surgery: impact on postoperative morbidity and extent of resection. J Neurosurg Sci 51:45-51, 2007

12. Castellano A, Bello L, Michelozzi C, Gallucci M, Fava E, Iadanza A, et al: Role of diffusion tensor magnetic resonance tractography in predicting the extent of resection in glioma surgery. Neuro Oncol 14:192-202, 2012

13. Cedzich C, Taniguchi M, Schäfer S, Schramm J: Somatosensory evoked potential phase reversal and direct motor cortex stimulation during surgery in and around the central region. Neurosurgery 38:962-970, 1996

14. Chang EF, Clark A, Smith JS, Polley MY, Chang SM, Barbaro NM, et al: Functional mapping-guided resection of low-grade gliomas in eloquent areas of the brain: improvement of long-term survival. Clinical article. J Neurosurg 114:566-573, 2011

15. Chen X, Weigel D, Ganslandt O, Fahlbusch R, Buchfelder M, Nimsky C: Diffusion tensor-based fiber tracking and intraoperative neuronavigation for the resection of a brainstem cavernous angioma. Surg Neurol 68:285-291, 2007

16. Claus EB, Horlacher A, Hsu L, Schwartz RB, Dello-Iacono D, Talos F, et al: Survival rates in patients with low-grade glioma after intraoperative magnetic resonance image guidance. Cancer 103:1227-1233, 2005

17. De Benedictis A, Duffau H: Brain hodotopy: from esoteric concept to practical surgical applications. Neurosurgery 68:1709-1723, 2011

18. De Witt Hamer PC, Robles SG, Zwinderman AH, Duffau H, Berger MS: Impact of intraoperative stimulation brain mapping on glioma surgery outcome: a meta-analysis. J Clin Oncol 30:2559-2565, 2012

19. DeAngelis LM: Brain tumors. N Engl J Med 344:114-123, 2001

20. Della Puppa A, De Pellegrin S, d'Avella E, Gioffrè G, Munari M, Saladini M, et al: Right parietal cortex and calculation processing: intraoperative functional mapping of multiplication and addition in patients affected by a brain tumor. $\mathbf{J}$ Neurosurg 119:1107-1111, 2013

21. Duffau H: Brain plasticity: from pathophysiological mechanisms to therapeutic applications. J Clin Neurosci 13:885897, 2006

22. Duffau H: Cognitive assessment in glioma patients. J Neurosurg 119:1348-1349, 2013 (Letter)

23. Duffau H, Capelle L, Denvil D, Sichez N, Gatignol P, Taillandier L, et al: Usefulness of intraoperative electrical subcortical mapping during surgery for low-grade gliomas located within eloquent brain regions: functional results in a consecutive series of 103 patients. J Neurosurg 98:764-778, 2003

24. Duffau H, Herbet G, Moritz-Gasser S: Toward a pluri-component, multimodal, and dynamic organization of the ventral semantic stream in humans: lessons from stimulation mapping in awake patients. Front Syst Neurosci 7:44, 2013

25. Duffau H, Lopes M, Arthuis F, Bitar A, Sichez JP, Van Effenterre R, et al: Contribution of intraoperative electrical stimulations in surgery of low grade gliomas: a comparative study between two series without (1985-96) and with (1996-
2003) functional mapping in the same institution. J Neurol Neurosurg Psychiatry 76:845-851, 2005

26. Duffau H, Moritz-Gasser S, Mandonnet E: A re-examination of neural basis of language processing: proposal of a dynamic hodotopical model from data provided by brain stimulation mapping during picture naming. Brain Lang 131:1-10, 2014

27. Forster MT, Senft C, Hattingen E, Lorei M, Seifert V, Szelényi A: Motor cortex evaluation by nTMS after surgery of central region tumors: a feasibility study. Acta Neurochir (Wien) 154:1351-1359, 2012

28. Frey D, Schilt S, Strack V, Zdunczyk A, Rösler J, Niraula B, et al: Navigated transcranial magnetic stimulation improves the treatment outcome in patients with brain tumors in motor eloquent locations. Neuro Oncol 16:1365-1372, 2014

29. Frey D, Strack V, Wiener E, Jussen D, Vajkoczy P, Picht T: A new approach for corticospinal tract reconstruction based on navigated transcranial stimulation and standardized fractional anisotropy values. Neuroimage 62:1600-1609, 2012

30. Fujiwara N, Sakatani K, Katayama Y, Murata Y, Hoshino T, Fukaya C, et al: Evoked-cerebral blood oxygenation changes in false-negative activations in BOLD contrast functional MRI of patients with brain tumors. Neuroimage 21:14641471,2004

31. Ganslandt O, Buchfelder M, Hastreiter P, Grummich P, Fahlbusch R, Nimsky C: Magnetic source imaging supports clinical decision making in glioma patients. Clin Neurol Neurosurg 107:20-26, 2004

32. Giussani C, Roux FE, Ojemann J, Sganzerla EP, Pirillo D, Papagno C: Is preoperative functional magnetic resonance imaging reliable for language areas mapping in brain tumor surgery? Review of language functional magnetic resonance imaging and direct cortical stimulation correlation studies. Neurosurgery 66:113-120, 2010

33. Haglund MM, Berger MS, Shamseldin M, Lettich E, Ojemann GA: Cortical localization of temporal lobe language sites in patients with gliomas. Neurosurgery 34:567-576, 1994

34. Henning Stieglitz L, Seidel K, Wiest R, Beck J, Raabe A: Localization of primary language areas by arcuate fascicle fiber tracking. Neurosurgery 70:56-65, 2012

35. Ius T, Angelini E, Thiebaut de Schotten M, Mandonnet E, Duffau H: Evidence for potentials and limitations of brain plasticity using an atlas of functional resectability of WHO grade II gliomas: towards a "minimal common brain." Neuroimage 56:992-1000, 2011

36. Jack CR Jr, Thompson RM, Butts RK, Sharbrough FW, Kelly PJ, Hanson DP, et al: Sensory motor cortex: correlation of presurgical mapping with functional MR imaging and invasive cortical mapping. Radiology 190:85-92, 1994

37. Jakola AS, Myrmel KS, Kloster R, Torp SH, Lindal S, Unsgård G, et al: Comparison of a strategy favoring early surgical resection vs a strategy favoring watchful waiting in lowgrade gliomas. JAMA 308:1881-1888, 2012

38. Jakola AS, Unsgård G, Myrmel KS, Kloster R, Torp SH, Lindal S, et al: Low grade gliomas in eloquent locations implications for surgical strategy, survival and long term quality of life. PLoS ONE 7:e51450, 2012

39. Kawashima A, Krieg SM, Faust K, Schneider H, Vajkoczy P, Picht T: Plastic reshaping of cortical language areas evaluated by navigated transcranial magnetic stimulation in a surgical case of glioblastoma multiforme. Clin Neurol Neurosurg 115:2226-2229, 2013

40. Keles GE, Lamborn KR, Berger MS: Low-grade hemispheric gliomas in adults: a critical review of extent of resection as a factor influencing outcome. J Neurosurg 95:735-745, 2001

41. Keles GE, Lundin DA, Lamborn KR, Chang EF, Ojemann G, Berger MS: Intraoperative subcortical stimulation mapping for hemispherical perirolandic gliomas located within or adjacent to the descending motor pathways: evaluation of 
morbidity and assessment of functional outcome in 294 patients. J Neurosurg 100:369-375, 2004

42. Kirsch HE, Zhu Z, Honma S, Findlay A, Berger MS, Nagarajan SS: Predicting the location of mouth motor cortex in patients with brain tumors by using somatosensory evoked field measurements. J Neurosurg 107:481-487, 2007

43. Kombos T, Picht T, Derdilopoulos A, Suess O: Impact of intraoperative neurophysiological monitoring on surgery of high-grade gliomas. J Clin Neurophysiol 26:422-425, 2009

44. Kombos T, Suess O, Ciklatekerlio O, Brock M: Monitoring of intraoperative motor evoked potentials to increase the safety of surgery in and around the motor cortex. J Neurosurg 95:608-614, 2001

45. Korvenoja A, Kirveskari E, Aronen HJ, Avikainen S, Brander A, Huttunen J, et al: Sensorimotor cortex localization: comparison of magnetoencephalography, functional MR imaging, and intraoperative cortical mapping. Radiology 241:213-222, 2006

46. Krieg SM, Buchmann NH, Gempt J, Shiban E, Meyer B, Ringel F: Diffusion tensor imaging fiber tracking using navigated brain stimulation-a feasibility study. Acta Neurochir (Wien) 154:555-563, 2012

47. Krieg SM, Sabih J, Bulubasova L, Obermueller T, Negwer $\mathrm{C}$, Janssen I, et al: Preoperative motor mapping by navigated transcranial magnetic brain stimulation improves outcome for motor eloquent lesions. Neuro Oncol 16:1274-1282, 2014

48. Krieg SM, Schäffner M, Shiban E, Droese D, Obermüller T, Gempt J, et al: Reliability of intraoperative neurophysiological monitoring using motor evoked potentials during resection of metastases in motor-eloquent brain regions. Clinical article. J Neurosurg 118:1269-1278, 2013

49. Krieg SM, Schnurbus L, Shiban E, Droese D, Obermueller T, Buchmann N, et al: Surgery of highly eloquent gliomas primarily assessed as non-resectable: risks and benefits in a cohort study. BMC Cancer 13:51, 2013

50. Krieg SM, Shiban E, Buchmann N, Gempt J, Foerschler A, Meyer B, et al: Utility of presurgical navigated transcranial magnetic brain stimulation for the resection of tumors in eloquent motor areas. J Neurosurg 116:994-1001, 2012

51. Krieg SM, Shiban E, Buchmann N, Meyer B, Ringel F: Presurgical navigated transcranial magnetic brain stimulation for recurrent gliomas in motor eloquent areas. Clin Neurophysiol 124:522-527, 2013

52. Krieg SM, Shiban E, Droese D, Gempt J, Buchmann N, Pape $\mathrm{H}$, et al: Predictive value and safety of intraoperative neurophysiological monitoring with motor evoked potentials in glioma surgery. Neurosurgery 70:1060-1071, 2012

53. Krieg SM, Sollmann N, Hauck T, Ille S, Foerschler A, Meyer $\mathrm{B}$, et al: Functional language shift to the right hemisphere in patients with language-eloquent brain tumors. PLoS ONE 8:e75403, 2013

54. Krieg SM, Sollmann N, Hauck T, Ille S, Meyer B, Ringel F: Repeated mapping of cortical language sites by preoperative navigated transcranial magnetic stimulation compared to repeated intraoperative DCS mapping in awake craniotomy. BMC Neurosci 15:20, 2014

55. Krieg SM, Tarapore PE, Picht T, Tanigawa N, Houde J, Sollmann N, et al: Optimal timing of pulse onset for language mapping with navigated repetitive transcranial magnetic stimulation. Neuroimage 100:219-236, 2014

56. Krings T, Schreckenberger M, Rohde V, Spetzger U, Sabri O, Reinges MH, et al: Functional MRI and 18F FDG-positron emission tomography for presurgical planning: comparison with electrical cortical stimulation. Acta Neurochir (Wien) 144:889-899, 2002

57. Kuhnt D, Bauer MH, Becker A, Merhof D, Zolal A, Richter $\mathrm{M}$, et al: Intraoperative visualization of fiber tracking based reconstruction of language pathways in glioma surgery. Neurosurgery 70:911-920, 2012

58. Leclercq D, Duffau H, Delmaire C, Capelle L, Gatignol P,
Ducros M, et al: Comparison of diffusion tensor imaging tractography of language tracts and intraoperative subcortical stimulations. J Neurosurg 112:503-511, 2010

59. Lefaucheur JP: Transcranial magnetic stimulation in the management of pain. Suppl Clin Neurophysiol 57:737-748, 2004

60. Lefaucheur JP, Drouot X, Ménard-Lefaucheur I, Nguyen JP: Neuropathic pain controlled for more than a year by monthly sessions of repetitive transcranial magnetic stimulation of the motor cortex. Neurophysiol Clin 34:91-95, 2004

61. Liégeois F, Cross JH, Gadian DG, Connelly A: Role of fMRI in the decision-making process: epilepsy surgery for children. J Magn Reson Imaging 23:933-940, 2006

62. Lurito JT, Lowe MJ, Sartorius C, Mathews VP: Comparison of fMRI and intraoperative direct cortical stimulation in localization of receptive language areas. J Comput Assist Tomogr 24:99-105, 2000

63. Mäkelä JP, Forss N, Jääskeläinen J, Kirveskari E, Korvenoja A, Paetau R: Magnetoencephalography in neurosurgery. Neurosurgery 61 (1 Suppl):147-165, 2007

64. Mikuni N, Okada T, Enatsu R, Miki Y, Hanakawa T, Urayama S, et al: Clinical impact of integrated functional neuronavigation and subcortical electrical stimulation to preserve motor function during resection of brain tumors. J Neurosurg 106:593-598, 2007

65. Nagarajan S, Kirsch H, Lin P, Findlay A, Honma S, Berger MS: Preoperative localization of hand motor cortex by adaptive spatial filtering of magnetoencephalography data. J Neurosurg 109:228-237, 2008

66. Neuloh G, Bien CG, Clusmann H, von Lehe M, Schramm J: Continuous motor monitoring enhances functional preservation and seizure-free outcome in surgery for intractable focal epilepsy. Acta Neurochir (Wien) 152:1307-1314, 2010

67. Neuloh G, Pechstein U, Cedzich C, Schramm J: Motor evoked potential monitoring with supratentorial surgery. Neurosurgery 54:1061-1072, 2004

68. Neuloh G, Pechstein U, Cedzich C, Schramm J: Motor evoked potential monitoring with supratentorial surgery. Neurosurgery 61 (1 Suppl):337-348, 2007

69. Neuloh G, Pechstein U, Schramm J: Motor tract monitoring during insular glioma surgery. J Neurosurg 106:582-592, 2007

70. Neuloh G, Schramm J: Are there false-negative results of motor evoked potential monitoring in brain surgery? Cent Eur Neurosurg 70:171-175, 2009

71. Neuloh G, Schramm J: Motor evoked potential monitoring for the surgery of brain tumours and vascular malformations. Adv Tech Stand Neurosurg 29:171-228, 2004

72. Neuloh G, Simon M, Schramm J: Stroke prevention during surgery for deep-seated gliomas. Neurophysiol Clin 37:383389,2007

73. Nimsky C, Ganslandt O, Hastreiter P, Wang R, Benner T, Sorensen AG, et al: Preoperative and intraoperative diffusion tensor imaging-based fiber tracking in glioma surgery. Neurosurgery 56:130-138, 2005

74. Nimsky C, Ganslandt O, Hastreiter P, Wang R, Benner T, Sorensen AG, et al: Preoperative and intraoperative diffusion tensor imaging-based fiber tracking in glioma surgery. Neurosurgery 61 (1 Suppl): 178-186, 2007

75. Nimsky C, Ganslandt O, Merhof D, Sorensen AG, Fahlbusch $\mathrm{R}$ : Intraoperative visualization of the pyramidal tract by diffusion-tensor-imaging-based fiber tracking. Neuroimage 30:1219-1229, 2006

76. Nossek E, Korn A, Shahar T, Kanner AA, Yaffe H, Marcovici $\mathrm{D}$, et al: Intraoperative mapping and monitoring of the corticospinal tracts with neurophysiological assessment and 3 -dimensional ultrasonography-based navigation. Clinical article. J Neurosurg 114:738-746, 2011

77. Ogawa S, Tank DW, Menon R, Ellermann JM, Kim SG, Merkle $\mathrm{H}$, et al: Intrinsic signal changes accompanying sen- 
sory stimulation: functional brain mapping with magnetic resonance imaging. Proc Natl Acad Sci U S A 89:59515955,1992

78. Ohue S, Kohno S, Inoue A, Yamashita D, Harada H, Kumon Y, et al: Accuracy of diffusion tensor magnetic resonance imaging-based tractography for surgery of gliomas near the pyramidal tract: a significant correlation between subcortical electrical stimulation and postoperative tractography. Neurosurgery 70:283-294, 2012

79. Ojemann G, Ojemann J, Lettich E, Berger M: Cortical language localization in left, dominant hemisphere. An electrical stimulation mapping investigation in 117 patients. J Neurosurg 71:316-326, 1989

80. Ojemann GA, Whitaker HA: Language localization and variability. Brain Lang 6:239-260, 1978

81. Ostrý S, Belšan T, Otáhal J, Beneš V, Netuka D: Is intraoperative diffusion tensor imaging at 3.0T comparable to subcortical corticospinal tract mapping? Neurosurgery 73:797-807, 2013

82. Ottenhausen M, Bodhinayake I, Banu M, Kesavabhotla K, Ray A, Boockvar JA: Industry progress report on neurooncology: Biotech update 2013. J Neurooncol 115:311-316, 2013

83. Ozawa N, Muragaki Y, Nakamura R, Hori T, Iseki H: Shift of the pyramidal tract during resection of the intraaxial brain tumors estimated by intraoperative diffusion-weighted imaging. Neurol Med Chir (Tokyo) 49:51-56, 2009

84. Papanicolaou AC, Simos PG, Breier JI, Zouridakis G, Willmore LJ, Wheless JW, et al: Magnetoencephalographic mapping of the language-specific cortex. J Neurosurg 90:85-93, 1999

85. Picht T, Krieg SM, Sollmann N, Rösler J, Niraula B, Neuvonen T, et al: A comparison of language mapping by preoperative navigated transcranial magnetic stimulation and direct cortical stimulation during awake surgery. Neurosurgery 72:808-819, 2013

86. Picht T, Schulz J, Hanna M, Schmidt S, Suess O, Vajkoczy P: Assessment of the influence of navigated transcranial magnetic stimulation on surgical planning for tumors in or near the motor cortex. Neurosurgery 70:1248-1257, 2012

87. Post A, Keck ME: Transcranial magnetic stimulation as a therapeutic tool in psychiatry: what do we know about the neurobiological mechanisms? J Psychiatr Res 35:193-215, 2001

88. Prabhu SS, Gasco J, Tummala S, Weinberg JS, Rao G: Intraoperative magnetic resonance imaging-guided tractography with integrated monopolar subcortical functional mapping for resection of brain tumors. Clinical article. J Neurosurg 114:719-726, 2011

89. Raabe A, Beck J, Schucht P, Seidel K: Continuous dynamic mapping of the corticospinal tract during surgery of motor eloquent brain tumors: evaluation of a new method. J Neurosurg 120:1015-1024, 2014

90. Robles SG, Gatignol P, Lehéricy S, Duffau H: Long-term brain plasticity allowing a multistage surgical approach to World Health Organization Grade II gliomas in eloquent areas. J Neurosurg 109:615-624, 2008

91. Rösler J, Niraula B, Strack V, Zdunczyk A, Schilt S, Savolainen P, et al: Language mapping in healthy volunteers and brain tumor patients with a novel navigated TMS system: evidence of tumor-induced plasticity. Clin Neurophysiol 125:526-536, 2014

92. Rossi S, Rossini PM: TMS in cognitive plasticity and the potential for rehabilitation. Trends Cogn Sci 8:273-279, 2004

93. Roux FE, Boulanouar K, Lotterie JA, Mejdoubi M, LeSage JP, Berry I: Language functional magnetic resonance imaging in preoperative assessment of language areas: correlation with direct cortical stimulation. Neurosurgery 52:13351347,2003
94. Roux FE, Boulanouar K, Ranjeva JP, Tremoulet M, Henry $\mathrm{P}$, Manelfe C, et al: Usefulness of motor functional MRI correlated to cortical mapping in Rolandic low-grade astrocytomas. Acta Neurochir (Wien) 141:71-79, 1999

95. Sanai N, Berger MS: Glioma extent of resection and its impact on patient outcome. Neurosurgery 62:753-764, 264-266, 2008

96. Sanai N, Berger MS: Intraoperative stimulation techniques for functional pathway preservation and glioma resection. Neurosurg Focus 28(2):E1, 2010

97. Sanai N, Mirzadeh Z, Berger MS: Functional outcome after language mapping for glioma resection. N Engl J Med 358:18-27, 2008

98. Satoer D, Vork J, Visch-Brink E, Smits M, Dirven C, Vincent A: Cognitive functioning early after surgery of gliomas in eloquent areas. J Neurosurg 117:831-838, 2012

99. Schiffbauer H, Berger MS, Ferrari P, Freudenstein D, Rowley HA, Roberts TP: Preoperative magnetic source imaging for brain tumor surgery: a quantitative comparison with intraoperative sensory and motor mapping. J Neurosurg 97:1333-1342, 2002

100. Schiffbauer H, Ferrari P, Rowley HA, Berger MS, Roberts TP: Functional activity within brain tumors: a magnetic source imaging study. Neurosurgery 49:1313-1321, 2001

101. Seidel K, Beck J, Stieglitz L, Schucht P, Raabe A: The warning-sign hierarchy between quantitative subcortical motor mapping and continuous motor evoked potential monitoring during resection of supratentorial brain tumors. J Neurosurg 118:287-296, 2013

102. Simos PG, Papanicolaou AC, Breier JI, Wheless JW, Constantinou JE, Gormley WB, et al: Localization of language-specific cortex by using magnetic source imaging and electrical stimulation mapping. J Neurosurg 91:787-796, 1999

103. Smith JS, Chang EF, Lamborn KR, Chang SM, Prados MD, Cha S, et al: Role of extent of resection in the long-term outcome of low-grade hemispheric gliomas. J Clin Oncol 26: $1338-1345,2008$

104. Sollmann N, Hauck T, Obermüller T, Hapfelmeier A, Meyer B, Ringel F, et al: Inter- and intraobserver variability in motor mapping of the hotspot for the abductor policis brevis muscle. BMC Neurosci 14:94, 2013

105. Stadlbauer A, Nimsky C, Buslei R, Salomonowitz E, Hammen T, Buchfelder M, et al: Diffusion tensor imaging and optimized fiber tracking in glioma patients: histopathologic evaluation of tumor-invaded white matter structures. Neuroimage 34:949-956, 2007

106. Stadlbauer A, Nimsky C, Gruber S, Moser E, Hammen T, Engelhorn T, et al: Changes in fiber integrity, diffusivity, and metabolism of the pyramidal tract adjacent to gliomas: a quantitative diffusion tensor fiber tracking and MR spectroscopic imaging study. AJNR Am J Neuroradiol 28:462-469, 2007

107. Stummer W, Reulen HJ, Meinel T, Pichlmeier U, Schumacher W, Tonn JC, et al: Extent of resection and survival in glioblastoma multiforme: identification of and adjustment for bias. Neurosurgery 62:564-576, 2008

108. Suess O, Suess S, Brock M, Kombos T: Intraoperative electrocortical stimulation of Brodman area 4: a 10-year analysis of 255 cases. Head Face Med 2:20, 2006

109. Szelényi A, Langer D, Beck J, Raabe A, Flamm ES, Seifert $\mathrm{V}$, et al: Transcranial and direct cortical stimulation for motor evoked potential monitoring in intracerebral aneurysm surgery. Neurophysiol Clin 37:391-398, 2007

110. Szelényi A, Langer D, Kothbauer K, De Camargo AB, Flamm ES, Deletis V: Monitoring of muscle motor evoked potentials during cerebral aneurysm surgery: intraoperative changes and postoperative outcome. J Neurosurg 105:675681,2006

111. Szelényi A, Senft C, Jardan M, Forster MT, Franz K, Seifert 
$\mathrm{V}$, et al: Intra-operative subcortical electrical stimulation: a comparison of two methods. Clin Neurophysiol 122:14701475,2011

112. Takahashi S, Vajkoczy P, Picht T: Navigated transcranial magnetic stimulation for mapping the motor cortex in patients with rolandic brain tumors. Neurosurg Focus 34(4):E3, 2013

113. Talacchi A, Santini B, Casartelli M, Monti A, Capasso R, Miceli G: Awake surgery between art and science. Part II: language and cognitive mapping. Funct Neurol 28:223239,2013

114. Talacchi A, Santini B, Savazzi S, Gerosa M: Cognitive effects of tumour and surgical treatment in glioma patients. J Neurooncol 103:541-549, 2011

115. Taniguchi M, Cedzich C, Schramm J: Modification of cortical stimulation for motor evoked potentials under general anesthesia: technical description. Neurosurgery 32:219226, 1993

116. Tarapore PE, Martino J, Guggisberg AG, Owen J, Honma SM, Findlay A, et al: Magnetoencephalographic imaging of resting-state functional connectivity predicts postsurgical neurological outcome in brain gliomas. Neurosurgery 71:1012-1022, 2012

117. Tarapore PE, Tate MC, Findlay AM, Honma SM, Mizuiri $\mathrm{D}$, Berger MS, et al: Preoperative multimodal motor mapping: a comparison of magnetoencephalography imaging, navigated transcranial magnetic stimulation, and direct cortical stimulation. J Neurosurg 117:354-362, 2012

118. Tassinari CA, Cincotta M, Zaccara G, Michelucci R: Transcranial magnetic stimulation and epilepsy. Clin Neurophysiol 114:777-798, 2003

119. Tergau F, Naumann U, Paulus W, Steinhoff BJ: Lowfrequency repetitive transcranial magnetic stimulation improves intractable epilepsy. Lancet 353:2209, 1999

120. Tomczak RJ, Wunderlich AP, Wang Y, Braun V, Antoniadis G, Görich J, et al: fMRI for preoperative neurosurgical mapping of motor cortex and language in a clinical setting. J Comput Assist Tomogr 24:927-934, 2000

121. Ulmer JL, Hacein-Bey L, Mathews VP, Mueller WM, DeYoe EA, Prost RW, et al: Lesion-induced pseudodominance at functional magnetic resonance imaging: implications for preoperative assessments. Neurosurgery 55:569-581, 2004
122. Vigneau M, Beaucousin V, Hervé PY, Duffau H, Crivello F, Houdé O, et al: Meta-analyzing left hemisphere language areas: phonology, semantics, and sentence processing. Neuroimage 30:1414-1432, 2006

123. Wen PY, Kesari S: Malignant gliomas in adults. N Engl J Med 359:492-507, 2008

124. Wu AS, Witgert ME, Lang FF, Xiao L, Bekele BN, Meyers $\mathrm{CA}$, et al: Neurocognitive function before and after surgery for insular gliomas. J Neurosurg 115:1115-1125, 2011

125. Wu JS, Zhou LF, Tang WJ, Mao Y, Hu J, Song YY, et al: Clinical evaluation and follow-up outcome of diffusion tensor imaging-based functional neuronavigation: a prospective, controlled study in patients with gliomas involving pyramidal tracts. Neurosurgery 61:935-949, 2007

126. Yetkin FZ, Mueller WM, Morris GL, McAuliffe TL, Ulmer JL, Cox RW, et al: Functional MR activation correlated with intraoperative cortical mapping. AJNR Am J Neuroradiol 18:1311-1315, 1997

127. Zhu FP, Wu JS, Song YY, Yao CJ, Zhuang DX, Xu G, et al: Clinical application of motor pathway mapping using diffusion tensor imaging tractography and intraoperative direct subcortical stimulation in cerebral glioma surgery: a prospective cohort study. Neurosurgery 71:1170-1184, 2012

128. Zolal A, Hejčl A, Vachata P, Bartoš R, Humhej I, Malucelli A, et al: The use of diffusion tensor images of the corticospinal tract in intrinsic brain tumor surgery: a comparison with direct subcortical stimulation. Neurosurgery 71:331340,2012

\section{Author Contributions}

Drafting the article: Ringel, Krieg, Ottenhausen. Critically revising the article: Ringel, Meyer. Reviewed submitted version of manuscript: all authors. Approved the final version of the manuscript on behalf of all authors: Ringel.

\section{Correspondence}

Florian Ringel, Department of Neurosurgery, Klinikum rechts der Isar, Technische Universität München, Ismaninger Str. 22, 81675 Munich, Germany. email: florian.ringel@1rz.tum.de. 